\title{
Blindness in schoolchildren: importance of heredity, congenital cataract, and prematurity
}

\author{
CALBERT I PHILLIPS, ' ANTHONY M LEVY,' MARJORIE NEWTON, ${ }^{3}$ AND \\ N LESLIE STOKOE'
}

From the 'Department of Ophthalmology, University of Edinburgh, and Princess Alexandra Eye Pavilion, Chalmers Street, Edinburgh; 'Southport General Infirmary, Scarisbrick New Road, Southport, Merseyside, PR8 6PH; and the ${ }^{3}$ Medical Research Council Clinical and Population Cytogenetics Unit, Western General Hospital, Edinburgh

SUMmary Of 99 children in the Royal Blind School, Edinburgh (which serves Scotland and part of N E England), 15 had optic atrophy (hydrocephalus 4, intracranial haemorrhage 2, prematurity 2, fetal distress 2 , birth asphyxia 2 , cerebral atrophy 1 , cardiac arrest during hernia operation 1 , and leukaemia 1). Fourteen had congenital cataract, 12 congenital retinal aplasia (Leber's congenital amaurosis) and 11 retinopathy of prematurity. There were small numbers in many other diagnostic categories, including three with non-accidental head injury. Mental retardation, spasticity, and nystagmus were frequent other correlates in all diagnostic categories. 'Very probably hereditary' was a conservative attribution in 36 , while 'probable' seemed appropriate for 12 - that is, almost $48 \%$ were hereditary. Only about 11 cases might have been prevented through genetic counselling, which testifies to the frequency of autosomal recessive hereditary disease, although no parents were consanguineous.

The Royal Blind School (RBS), Edinburgh, is a residential school for the severely visually handicapped with a visual acuity almost invariably $3 / 60$ or less or, occasionally, with very severe field loss. Our diagnostic survey of its 99 pupils does not include all Scottish blind children of school age, because educability is another criterion for admission, though many of the pupils are mentally retarded, some quite severely so. We have no information about blind children in other institutions for the very severely (multiply) handicapped. The only other school for the blind in Scotland is a small one in Glasgow: it has few residents, and caters for the deaf and the blinddeaf as well as some blind. The catchment area of the Edinburgh school also includes the north of England, especially the north-east, since a blind school in

Correspondence to Professor C I Phillips, Department of Ophthalmology, University of Edinburgh and Princess Alexandra Eye Pavilion, Chalmers Street, Edinburgh EH3 9HA.
Newcastle upon Tyne closed; six pupils have present home addresses in England.

This survey of the RBS is more comprehensive than our previous statistics of only hereditary cases there.' Another motive for the study was to compare the diagnoses in Scotland with those in 67 pupils in the Blind School of Yamanashi Prefecture, $120 \mathrm{~km}$ south-west of Tokyo, Japan.' One common observer in each study should make comparisons reasonably valid. The present information is also a selective update of the comprehensive survey of 776 blind children in England and Wales by Fraser and Friedmann published in $1967^{3}$ and of Sorsby's study of blindness in all age groups for 1963-8 in the same countries $^{+}$and of the Report of the Department of Health and Social Security for England 1969-76.

\section{Material and methods}

Permission to be included in this survey was obtained from the parents of all except two pupils. Ages 
ranged from 5 to 18 years. Each pupil was fully examined and the case records at the Royal Blind School scrutinised. Binocular indirect ophthalmoscopy was often essential. Supplementary information was sometimes required from hospital records. A few patients were very difficult to examine, especially when mentally handicapped, even though the children and parents tried hard to be co-operative. In them more reliance was placed on records of previous examinations under anaesthesia and electrodiagnostic tests. The family history was obtained from parents, case records at the Royal Blind School or hospital, teachers, or our own records in our ophthalmic genetics clinic. Several children and families were already known to us in detail. ${ }^{6.9}$

\section{Results}

The large amount of information collected has been condensed into Table 1 . The main cause of blindnes has determined the classification, but some important coexistent abnormalities, ophthalmic and general, are mentioned in the last column headed 'Comments and complications.' Nystagmus was so frequent a complication that it is mentioned only in the two females in whom it was the primary cause of visual handicap.

'Optic nerve atrophy' was applied to 15 cases, but it was further divided into numerous smaller subgroups with a more fundamental diagnosis. Four cases of optic atrophy have been separately listed under injury, head, and one each under brain tumour and abscess. Of the 15 cases included under 'optic nerve atrophy' hydrocephalus accounted for four, nontraumatic intracranial haemorrhage for two (one premature and one with porencephaly,) prematurity for two, and fetal distress and birth asphyxia for two each, although at least one of the last may have had a more basic correlate, microcephaly. One each was attributed to cerebral atrophy, cardiac arrest during a hernia operation (a definitely iatrogenic disease), and leukaemia with or without virus infection or its drug treatment. Optic nerve hypoplasia (one) is not included in these 15 .

There were 12 cases of congenital cataract, almost all operated upon in infancy. The mendelian dominant cases (four) seem to have fewer associated systemic diseases than the sporadic (six) or adopted (two) ones.

Another 12 cases were classified under retinal aplasia (Leber's congenital amaurosis), often with other handicaps (Table 1).

Ranking third of the single clinical entities (apart from the optic atrophy 'group' above), and closely rivalling congenital cataracts at 12 cases and retinal aplasia at 12 cases, was retinopathy of prematurity with 11 cases. Of these, seven were mentally retarded with other serious correlates (see last column of Table 1), while three others had other serious complications but not mental retardation; Table 2 presents their birth weights, and Table 3 relates birth weights to intelligence quotient (IQ) and sex.

Only three cases of aniridia were definitely dominant. It is interesting that three of the four sporadic cases had the syndrome of a deletion of the short arm of chromosome 11 and mental retardation; one of these three also had a Wilms tumour.

Under the diagnosis 'injury, head' are a minimum of three with definitely non-accidental trauma. The possibility exists in more than one other case, but the evidence was not good enough to be certain of that cause. One patient was probably blinded indirectly by epilepsy, through head injury.

Although the numbers with other diagnoses are small (Table 1), they make up in sum a significant proportion of the pupils, of special interest because many are hereditary in origin (see 'Discussion').

Table 4 presents a classification by hereditary pattern when present. In 40 cases there was not even a suspicion of a hereditary cause. 'Very probable,' however, is a conservative description of the level of likelihood in 36; 'probable' seemed reasonable in 12; 'possible' (five) and 'suspected' (five) made up the balance of 58. (The 99th patient with cataract associated with $\mathrm{Rh}$ factor haemolytic disease was not classified as either genetic or non-genetic.)

\section{Discussion}

At the beginning of each session we survey new admissions to this blind school for hereditary disease. Parents may have completed their families by the time a blind child is old enough for school education, so that genetic counselling, if appropriate and not already given, is usually superfluous. Towards the end of each session we see the school leavers to offer genetic information if consent is given; it is also important for teenagers who do not have hereditary disease to be reassured on that score. Parents are also invited to attend these sessions with their teenage children, but very few do so.

We had the impression of a high prevalence of hereditary disease at various levels of probability in these children. Hence the decision to make this comprehensive survey of all pupils at the school throughout session 1984-5. We rate 36 of the 99 pupils as having 'very probable' hereditary disease, 12 as 'probable,' while another 10 are either 'possible' (five) or 'suspected' (five) (Tables 1 and 4). Accordingly heredity is responsible for between 48 and 58 of the 99 blind pupils at this school.

Mainly because so many cases are (very) probably 
Table 1 Causes of blindness: diagnosis and heredity

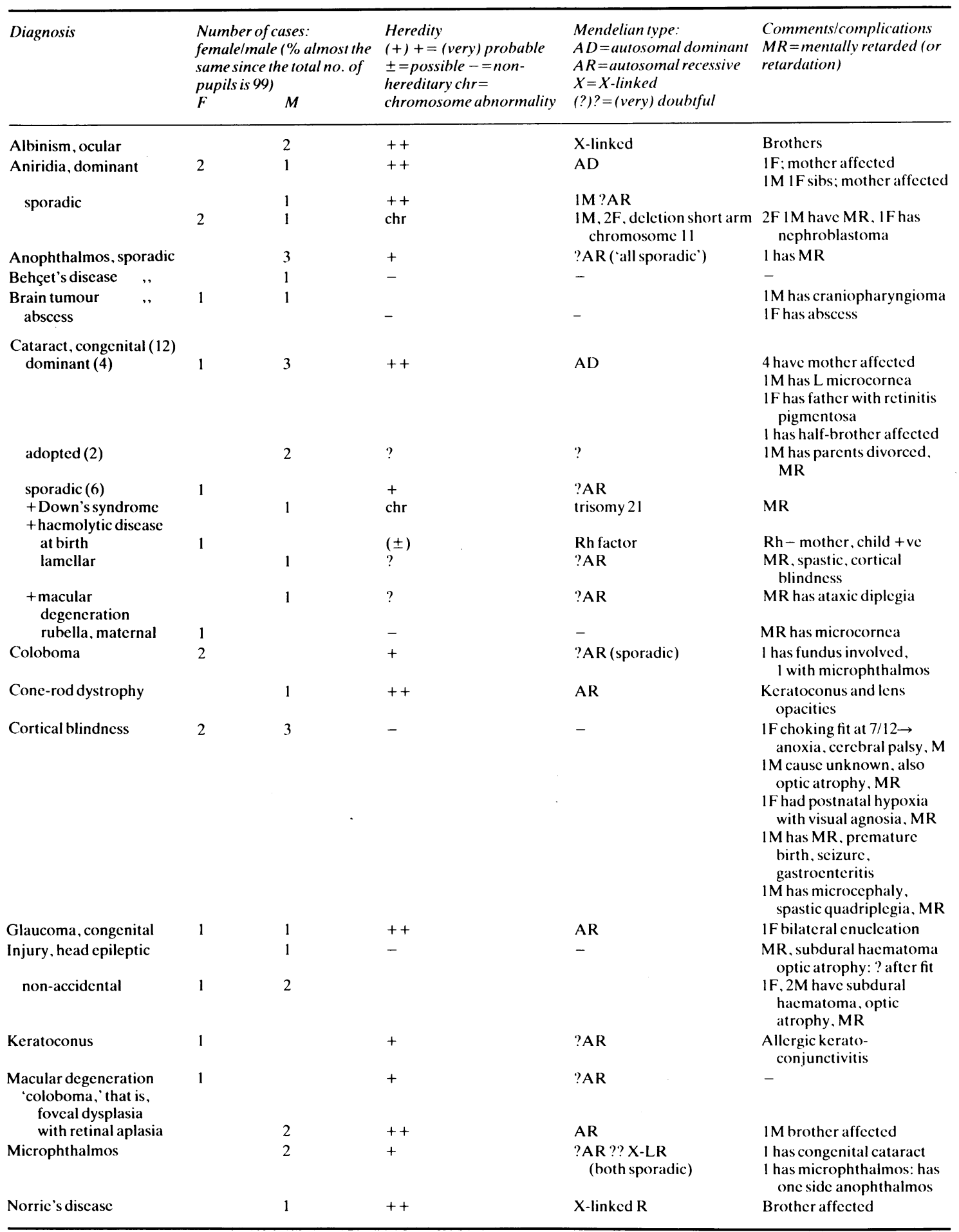


Table 1 Causes of blindness: diagnosis and heredity (continued)

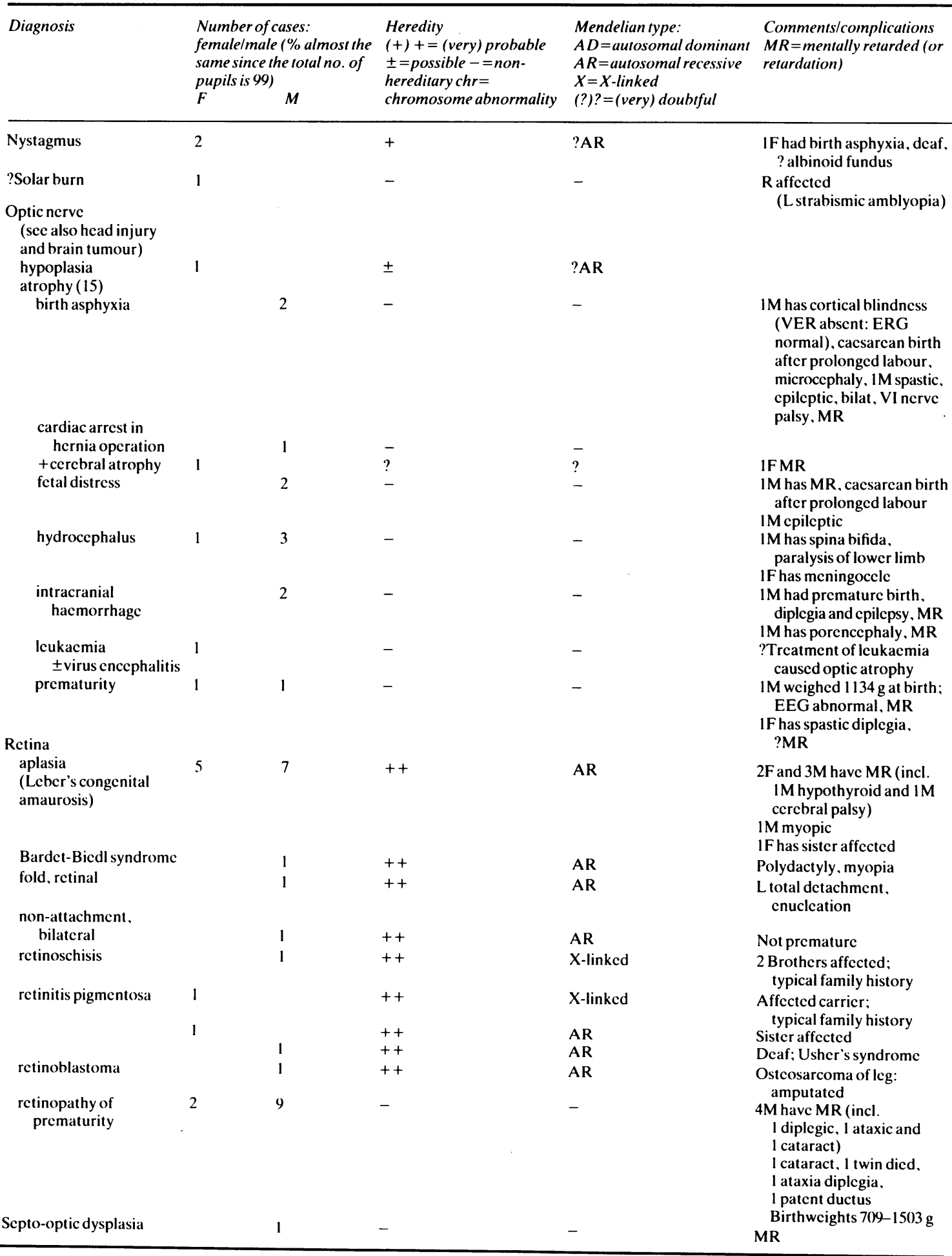


Table 2 Retinopathy of prematurity

\begin{tabular}{lll}
\hline Year of birth & Number & Birth weight ing \\
\hline 1966 & 1 & 1304 \\
$1967-70$ & 0 & - \\
1971 & 3 & $1304,1474,1503$ \\
1972 & 2 & 709,1361 \\
1973 and 74 & 0 & - \\
1975 & 1 & 907 \\
1976 and 77 & 0 & - \\
1978 & 1 & 998 \\
1979 & 2 & $<907,992$ \\
1980 & 1 & 1247 \\
\hline
\end{tabular}

Table 3 Birthweight and IQ

\begin{tabular}{|c|c|c|c|c|c|c|}
\hline \multirow[t]{2}{*}{ Birth weight } & \multicolumn{2}{|c|}{ Total } & \multicolumn{2}{|c|}{ Low IQ } & \multicolumn{2}{|c|}{ Normal IQ } \\
\hline & $F$ & $M$ & $F$ & $M$ & $F$ & $M$ \\
\hline$<2.5 \mathrm{~kg}$ & 7 & 15 & 3 & 12 & 4 & 3 \\
\hline$\geqslant 2.5 \mathrm{~kg}$ & 26 & 45 & 7 & 16 & 19 & 29 \\
\hline Not known & 1 & 5 & - & 4 & 1 & 1 \\
\hline Totals & 34 & 65 & 10 & 32 & 24 & 33 \\
\hline
\end{tabular}

autosomal recessive in causation (42), few could be said to be preventable by the parents' refraining from having children. Only the seven dominant cases, and possibly one of the two with X-linked ocular albinism, the $\mathrm{X}$-linked retinoschisis, the $\mathrm{X}$-linked retinitis pigmentosa, and the case of autosomal recessive retinitis pigmentosa might have been avoidable through genetic counselling. The boy with Norrie's disease and his younger brother, also affected but not yet at school, probably had inherited a mutation from his mother. ${ }^{6}$ The girl from a family with definite $\mathrm{X}$-linked retinitis pigmentosa' may be showing a surprisingly severe manifestation of the carrier state. Her mother is a carrier, but the girl's electroretinogram (ERG) is not typical, and high myopia is a factor in her 'blindness'; she has no chromosome abnormalities which might have offered an explanation for this anomaly.

Consanguinity of parents was totally absent, which eliminated one support for a diagnosis of recessive disease. In contrast, in Yamanashi, Japan, $12 \%$ of the non-environmental cases had some consanguinity of parents, the majority being full cousins. ${ }^{2}$ However, that cultural difference is probably diminishing with a fall in the rate of consanguineous marriage in Japan, once the highest in the world."

All but one of the 12 cases of the remarkably common retinal aplasia was sporadic, as would be expected in autosomal recessive disease. The one exception had an elder sister affected, but no counselling was given to the parents after the first child was diagnosed - which also applied to the family of the girl with autosomal recessive retinitis pigmentosa. It is interesting that no cases of retinal aplasia (Leber's congenital amaurosis) were seen in Yamanashi, Japan. $^{2}$

Many diseases may be difficult for a non-geneticist to attribute to an autosomal recessive cause. ${ }^{7}$ The diagnosis will be very difficult in very rare diseases, as in at least one of the males with macular 'coloboma' (foveal dysplasia) plus retinal aplasia - an affected elder brother makes a recessive cause likely ${ }^{*}-$ and in bilateral non-attachment of retina." Indeed there may well be other cases in Table 1 with unsuspected recessive disease, and it is very likely that the catalogue of such diseases in general is still incomplete.

Although bilateral congenital cataract is generally thought to have a good prognosis, there are 12 out of 99 cases in this blind school. The proportion that

Table 4 Probability of heredity as a cause of blindness

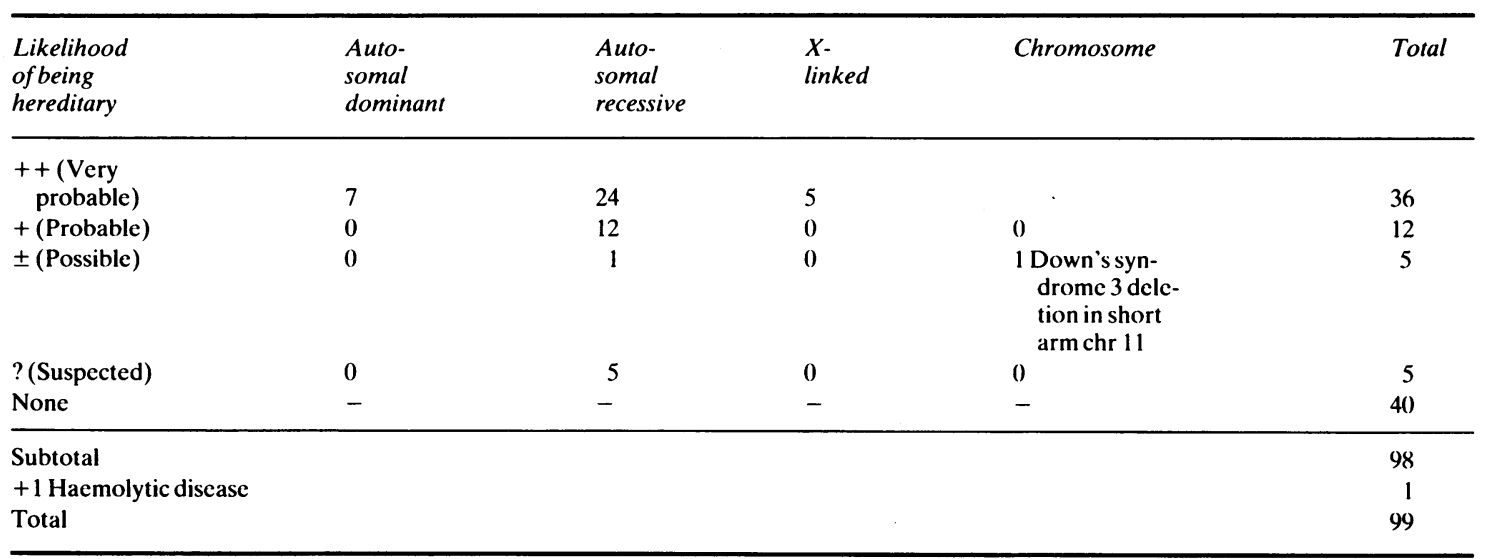


these 12 constitute of all cases of congenital cataract, presumably most coping adequately enough after operation, is unknown. The apparently unrelated systemic diseases in the sporadic cases may be interpreted as suggesting they are not hereditary in origin, although recessive inheritance is possible. There were twice as many males (eight) as females (four), an inexplicable inequality also noted in childhood cataract blindness in $1967 .{ }^{12}$ The proportion of cases of blindness due to congenital cataract was even higher in Yamanashi (16/67) than in Edinburgh (12/ 99), the latter figure being very similar to that for England in the age group 5-15 in 1969-76. ${ }^{13}$

In general, males (65) considerably outnumber females (34), yet only five cases have X-linked recessive disease (of which one is actually a female). The female:male ratio, in the very probably and probably hereditary group, excluding the five cases with X-linked disease was, very surprisingly, 19:27. Perhaps even more surprising was the ratio in the definitely non-hereditary group, namely 11:29. In the Yamanashi Blind School survey a similar underrepresentation of females compared with males was found both in the hereditary group (12 F to $21 \mathrm{M}$ in the dominant and (very) probably autosomal recessive) and the non-hereditary group ( $5 \mathrm{~F}$ to $13 \mathrm{M})$. Overall in Japan there were $20 \mathrm{~F}$ to $28 \mathrm{M}$ in the $\leqslant 18$ years age group, which excludes the $3 \mathrm{~F}$ and $16 \mathrm{M}$ in the $\geqslant 19$ years group, in whom 'retraining' may have been more favoured by, or for, males. The $5 \mathrm{~F}: 7$ $M$ ratio in our retinal aplasia cases may easily be due to chance or to lack of differentiation within a heterogeneous group. The $2 \mathrm{~F}: 9 \mathrm{M}$ ratio in retinopathy of prematurity is difficult to explain. Neither Sorsby's statistics ${ }^{1+}$ nor those of Fraser and Friedmann ${ }^{15}$ show a male excess in retrolental fibroplasia as it was then called, but two other reports have recorded a preponderance of males, ${ }^{1617}$ attributed to their greater immaturity than girls for a given birthweight.

In the group with low birthweight $(<2.5 \mathrm{~kg})$ and low IQ there is a preponderance of males, $3 \mathrm{~F}$ to $12 \mathrm{M}$, but in the small group with a low birthweight but normal IQ there is no significant difference, $4 \mathrm{~F}$ to $3 \mathrm{M}$ (Table 3). An excess of males is also seen in those with normal IQ and normal birthweight, $19 \mathrm{~F}$ to $29 \mathrm{M}$, and even more so in those with low IQ and normal birthweight, $7 \mathrm{~F}$ to $16 \mathrm{M}$. In six children, $1 \mathrm{~F}$ and $5 \mathrm{M}$, the birthweight was not known; $4 \mathrm{M}$ had low IQ, and $1 \mathrm{~F}$ and $1 \mathrm{M}$ were mentally normal.

The excess of males is difficult to understand. More male babies destined to be blind may survive for some reason. However, the parents of male blind children may feel that these boys should have every educational advantage available, even if this means residential schooling far from home. They may prefer to keep blind girls at home, regarding them as ineducable, or send them to homes for the multiply handicapped, perhaps feeling that education may not be so important for them and also perhaps being unwilling to allow their daughters to live away from home at an early age. Table 3 shows that the excess of males is marked in the low IQ group, which is consistent with these explanations.

The much greater apparent prevalence of optic atrophy $(38 \%$ of blind males and the same proportion of blind females) aged 5-15 in England $1969-76^{13}$ than in our series (15/99) and in the Japanese series (1/67) may be at least in part due to the use of that diagnosis as a broader category in the English series..$^{13}$ Indeed, optic atrophy is a very imprecise diagnosis.

In Yamanashi $14.5 \%$ of the school age children had retinopathy of prematurity. However, the youngest was 11 years old, which may indicate the disappearance in Japan of this disease, which has been described as iatrogenic. Fraser and Friedmann record figures which clearly show the epidemic in England and Wales between 1946 and $1956 .{ }^{18}$ Our Table 2 may be interpreted as supporting the view sometimes expressed that the disease in Britain, having almost disappeared around the mid-1970s, has recrudesced in the last decade. This has been explained by a recent trend towards high-technology rescue of ever smaller weight premature babies who would not previously have survived. Evidence in Table 2 may support that. Of those with births between 1966 and 1972, only one weighed less than $1000 \mathrm{~g}$, whereas during $1975-80$ only one weighed more than $1000 \mathrm{~g}$. Similarly, the latter evidence would support a paediatrician's claim that measures to prevent this disease have been successful in premature babies with a weight of $1000 \mathrm{~g}$ or more. Our preoccupation with sight, however, should not blind us to the multiple handicaps both in this important subgroup and in all the other pupils. Ophthalmic morbidity from prematurity is presumably more common than frank ophthalmic mortality (that is, blindness), so that blindness statistics underestimate the penalty from prematurity. Furthermore, prematurity is a cause of many non-ocular defects in the visual system (Table 1) and of course in many other systems.

Ophthalmologists, having chosen a specialty which absolves them almost entirely from dealing with the problems of general disabling chronic disease and dysthanasia"1 (unpleasant or painful death, compare euthanasia), may be oversensitive to the multiple handicaps in some unfortunate patients. Paediatricians (and geriatricians, among others) have chosen specialties which demand involvement with patients on many difficult risk-taking occasions, including resuscitation and survival. Vicarious responsibility 
by parents (or other relatives) and doctors for decision making on behalf of premature and predictably multihandicapped, mentally retarded, sightless, and insightless babies (or others) has attracted more critical discussion recently. ${ }^{19} 211$

There were three victims of injury euphemistically called non-accidental, all being mentally retarded. No such diagnoses were made in the Yamanashi Japan, survey.'2

Scotland produced only one case in which high myopia may have been a contributory factor (the female probable carrier of $\mathrm{X}$-linked retinitis pigmentosa), whereas 5/67 were found in Yamanashi. ${ }^{2}$ It is surprising that one case of Behçet's disease, with a very well justified diagnosis, was found in Scotland. Only one was also found in Yamanashi Blind School, but the disease is far more prevalent in Japan $10 / 100000$ compared with $0 \cdot 6 / 100000$ in Britain. ${ }^{22}$

The staff at the Royal Blind School have a clear impression of an increase in multiple handicap among the pupils, but that may well result from a reduction in the prevalence of 'pure' blindness, so that more places are available for the multiply handicapped who previously had to go to other institutions. As in Yamanashi, Japan, we have been impressed by the happy atmosphere among the pupils in the Blind School and the very high standard of care and education provided by the very concerned teachers and other staff. The staff:pupil ratio is necessarily high. Their very sheltered environment and the sharing of their affliction with many blind peers help the blind children to minimise their great misfortune, albeit at high economic cost. It is probably easier to become reconciled to blindness or other handicap starting from birth or early childhood than to later blindness. However, at the end of their school days, their problems increase considerably, as they compete in the sighted world for training and employment. We may be guilty of overvaluing sight, as sighted individuals with a professional concern with alleviating defects in vision. The information we provide on hereditary risks (we never volunteer advice) in our ophthalmic genetics clinic probably has less effect than we originally hoped and expected, but does probably make some contribution to the prevention of blindness, often of a lifetime's duration.

\section{References}

1 Phillips CI, Stokoe NL, Hughes HE. An ophthalmic genetics clinic. Trans Ophthalmol Soc UK 1975; 95: 472-6.

2 Tsukahara S, Sasamoto M, Watanabe I, Phillips CI. Diagnostic survey at Yamanashi School for the Blind: importance of heredity. Jpn J Ophthalmol 1985; 29: 315-21.

3 Fraser GR, Friedmann AI. The causes of blindness in childhood. Baltimore: Johns Hopkins Press, 1967.

4 Sorsby A. The incidence and causes of blindness in England and Wales 1963-8. Reports on Public Health and Medical Subjects no. 128. Department of Health and Social Security. HMSO, 1972.

5 Department of Health and Social Sccurity Blindness and partial sight in England 1969-1976. Reports on Public Health and Medical Subjects no. 129. HMSO, 1979.

6 Phillips CI, Newton MS, Duvall J, Holloway S, Levy AM. Probably Norric's discase duc to mutation. Br J Ophthalmol 1986; 70: 305-13.

7 Phillips CI, Newton MS. Beware recessive genes. Lancet 1981 ii: 293-7.

8 Phillips CI, Stokoe NL, Newton MS. Congenital macular 'coloboma' and retinal aplasia: a sibship of two males. Acta Ophthalmol (Kbh) 1981; 59: 894-9(0).

9 Phillips CI, Newton MS, Gosden CM. Procreative instinct as a contributory factor to prevalence of hereditary blindness. Lancet 1982 i: $1169-72$.

10 Nakajima A. Genetic eye diseases and blindness. Nippon Ganka Gakkai Zasshi 1982 86: 1834-58.

11 Phillips CI, Leighton DA. Congenital hereditary non-attachment of retina: a sibship of two. Acta Ophthalmol (Kbh) 1973; 51: 425-33.

12 Fraser GR, Fricdmann AI. The causes of blindness in childhood. Baltimore: Johns Hopkins Press, 1967: 68, 207.

13 Department of Health and Social Security. Blindness and Partial Sight in England 1969-1976. Reports on Public Health and Medical Subjects no. 129. HMSO, 1979: 7.

14 Sorsby A. The incidence and causes of blindness in England and Wales 1963-68. Reports on Public Health and Medical Subjects no. 128. Department of Health and Social Security. HMSO, 1972: 10, Tablc 8, 48, Tablc 1b.

15 Fraser GR, Fricdmann AI. The causes of blindness in childhood. Baltimore: Johns Hopkins Press, 1967: 114.

16 Conference on retrolental fibroplasia. Retrolental Fibroplasia in the United Kingdom. A report to the Medical Research Council. Br Med J 1955; ii: 78-82.

17 Boyd JT, Hirst KM. Incidence of retrolental fibroplasia in England and Wales in 1951. Br Med J 1955; ii: 83-5.

18 Fraser GR, Fricdmann AI. The causes of blindness in childhood. Baltimore: Johns Hopkins Press, 1967: 118, Table XIV-7.

19 Tindall G. High-tech medicine: when to say no. J $R$ Soc Med 1986; 79: 56-7.

20 Whitelaw A. Death as an option in neonatal intensive care. Lancet 1986; ii: $328-31$.

21 Editorial: Dysthanasia. N Y State J Med 1975; 75: 842.

22 Jones GD. Behçet's syndrome. N Engl J Med 1979; 301: 431-2.

Accepted for publication 16 September 1986. 